\title{
ROBOTIC RECTOSIGMOIDECTOMY - PIONEER CASE REPORT IN BRAZIL. Current scene in colorectal robotic surgery
}

\author{
Marcelo AVERBACH, Pedro POPOUTCHI, Oswaldo Wiliam MARQUES Jr., \\ Ricardo Z. ABDALLA, Sérgio PODGAEC and Maurício Simões ABRÃo
}

\begin{abstract}
Laparoscopic colorectal surgery is believed to be technically and oncologically feasible. Robotic surgery is an attractive mode in performing minimally-invasive surgery once it has several advantages if compared to standard laparoscopic surgery. The aim of this paper is to report the first known case of colorectal resection surgery using the robotic assisted surgical device in Brazil. A 35-year-old woman with deep infiltrating endometriosis with rectal involvement was referred for colorectal resection using $d a$ Vinci $i^{\text {ब }}$ surgical system. The authors also reviewed the most current series and discussed not only the safety and feasibility but also the real benefits of robotic colorectal surgery.

HEADINGS - Robotics. Laparoscopy. Endometriosis, surgery. Colon, sigmoid, surgery. Rectum, surgery.
\end{abstract}

\section{BACKGROUND}

The 90's has testified a revolution in surgeries with the advent of laparoscopy. This technique has offered many advantages as shorter hospital stay, less postoperative pain and discomfort, decreased blood loss, less scarring and improved appearance. Laparoscopy has been chosen for many surgical procedures. Despite of the developed experience in laparoscopic surgery, most complex procedures were less accepted due to its ergonomic limitation, 2D vision and instruments without specific articulations. Since da Vinci Surgical System $^{\circledR}$ was cleared by The U.S. Food and Drug Administration (FDA) in 2000, the robotic surgery has become an attractive option within minimally-invasive surgery. This technology intends to substitute the most complex laparoscopic surgeries considering its enhanced capabilities that provide surgeons a high-definition 3D vision system, greater precision and tremor absence.

The purposes of this brief communication are, first to report the pioneer experience in robot-assisted rectosigmoidectomy in surgical treatment of deep endometriosis, and second to relate the current scene of colorectal robotic surgery.

\section{METHODS}

A 35-year-old patient with infertility and cyclic rectal bleeding (for 4 months) complaints, pain for defecate and abdominal distention. Nulipara underwent to an unsuccessful in vitro fertilization 1 year ago. A pelvis magnetic resonance imaging showed a mass covering the sigmoid colon with $6 \mathrm{~cm}$ extension to $14 \mathrm{~cm}$ from rectal border, cecum appendix, right tube and bladder involvement. A transvaginal ultrasound after bowel preparation confirmed the lesion which occupied $40 \%$ of rectal circumference.

A rectosigmoidectomy was proposed for treatment with retrocervical endometriosis, vesical and oophoroplasty exeresis by using robotics. The surgery was done in May 27th 2008, formed by a multidisciplinary team of surgeons and gynecologists who have concluded the robotic training.

da Vinci Surgical System ${ }^{\circledR}$ (Intuitive Surgical, Inc., Sunnyvale, CA, USA) technology was used. The surgical technique was similar to laparoscopic one. The first trocar $12 \mathrm{~mm}$ was introduced at the umbilical region, assisted by a Veress needle and a pneumoperitoneum with $\mathrm{CO}_{2}$ was established with intra-abdominal pressure of $12 \mathrm{~mm} \mathrm{Hg}$. Two trocars of $8 \mathrm{~mm}$ were used, connected to the robot arms and controlled by the surgeon using the console, one arm for the left flank and the other for the right, slightly above than the ones used in conventional laparoscopy. Two additional punctures, one measuring $12 \mathrm{~mm}$ at right iliac fossa and other at right hypochondrium, were done in order to help the assistant with vacuum and irrigator and later for linear stapler incision. The same incision of $12 \mathrm{~mm}$ was enlarged around $4 \mathrm{~cm}$ for the piece resection. The team was formed by a colorectal surgeon and a gynecologist and they took turns at the console, two assistants, one of them maneuvering the

Hospital Sírio Libanês - Centro de Treinamento em Cirurgia Robótica, São Paulo, SP, Brasi

Correspondence: Dr. Marcelo Averbach - Rua Barata Ribeiro, 414 - cj 65 - São Paulo, SP - 01308-000, Brazil. E-mail: maverbach@uol.com.br 
uterine manipulator and a surgical instrumentalist qualified to use the specific instrument. The procedure kept the same steps by the group, with medial-to-lateral colon dissection releasing adherences, rectum section and resection of additional sources of the disease at peritoneum, bladder and oophoroplasty. An additional suture at bladder was easily made by the articulated instruments. The trocater incision at the right iliac fossa was enlarged around $4 \mathrm{~cm}$ for the piece resection and extraperitoneal colorectal anastomosis was constructed by double stapling technique. The abdominal cavity was drained.

\section{RESULTS}

The surgery was uneventful. Operative time lasted 5 hours, considering 90 minutes for robotic system set up. The postoperative evolution was satisfactory. The patient left the hospital at the 5th postoperative day just for additional precaution. An anatomical pathology examination showed that the intestinal wall was involved in three regions, occupying $40 \%$ of rectal circumference. The resection borders were free. The only event happened was the colorectal anastomosis dilatation through colonoscopy at the 3rd month after the procedure. The patient is asymptomatic after 15 months of observation.

\section{DISCUSSION}

The robotic surgery or robotic-assisted laparoscopic surgery is a minimally-invasive surgery modality that presents some differences compared to conventional laparoscopy. The use of a robotic system brought advantages in exchanging skills from open surgery to laparoscopic camp. The 3D image of the procedure and a greater precise micro-movement of the instruments, reaching a $360^{\circ}$ rotation, are characteristics that result into a smaller learning curve and an advantage in reconstructive surgeries of higher complexity. Others details that should be considered, are the ergonomic and tremor absence which allows the surgeon to practice delicate dissections and sutures with comfort and precision, especially where a surgical camp is limited.

However, the robotic system has several drawbacks. The first and most important drawback is a lack of both tactile sensation and tensile feedback to the surgeon. Tissue damage can occur easily during traction by the robotic arm and during movement of the robotic instrument and suture material can be cut. The second drawback is that the docking and separation procedure of a robotic cart from the patient is a time consuming procedure. It can result into a problematic situation sometimes when prompt open conversion is necessary. The third drawback is the high cost in using the robotic system. The price of one robotic system is more than 2,000,000 US dollars. In 2009, the results of a multinational interdisciplinary consensus conference for the robotic pelvic surgery were published. The authors concluded that while robotic prostatectomy has become the most widely accepted method of prostatectomy, robotic hysterectomy and proctectomy remain far less widely accepted. The theoretical benefits of the increased degrees of freedom and threedimensional visualization may be outweighed in these areas by the loss of haptic feedback, increased operative times, and increased cost.

The da Vinci Surgical System ${ }^{\circledR}$ comprises three separate components: a surgeon's console where the surgeon sits, a patient-side robotic cart with four arms manipulated by the surgeon, and an electronic tower holding video and air inflation equipment. The surgeon can use three or four robotic arms, including the camera, and performs the surgery by manipulating the robotic controls in the console.

Nowadays, Urology is the specialty that most gets benefit from robotic-assisted surgery due to its high technical difficulty in complex procedures such radical prostatectomy and laparoscopic pyeloplasty. After the first robotic-assisted colecistectomy in 1997, there are been described a huge variety of simple or complex procedures. The most ordinary and practiced gastrointestinal robotic surgeries are colecistectomy, hiatoplasty, Heller myotomy and gastric bypass in Y-de-Roux.

Since Weber et al. ${ }^{(5)}$ performed the first robotic colectomies in 2001, the incidence of robotic colectomies grown. In 2004, D'Annibale et al. ${ }^{(2)}$ reported 53 robotic colorectal surgeries and 22 cases of malignant colorectal disease were contained. They concluded that robotic techniques could achieve the same operative and postoperative results compared to conventional laparoscopic techniques. The concept of robotic total mesorectal excision for rectal cancer was first reported by Pigazzi et al. in $2006^{(3)}$. They compared shortterm outcomes between robotic total mesorectal excision and laparoscopic total mesorectal excision. In that study, they concluded that robotic low anterior resection with total mesorectal excision and autonomic nerve preservation was feasible. Baik et al. ${ }^{(1)}$ reported in 2008, the first prospective randomized trial comparing robotic low anterior resection and laparoscopic low anterior resection. Eighteen cases of robotic low anterior resection were compared with 18 cases of laparoscopic low anterior resection. The results showed the feasibility and safety of robotic low anterior resection and better mesorectal grade in the robotic low anterior resection group even though they could not find statistical differences between the groups. In 2008, Spinoglio et al. ${ }^{(4)}$ reported their initial first 50 cases of robotic colorectal surgeries. Their conclusion was that robotic colon surgery was feasible and safe but a longer operating time was needed.

Punctures have larger diameter for robotic system compared to conventional laparoscopic: $12 \mathrm{~mm}$ punctures are equivalent to $10 \mathrm{~mm}$ and $8 \mathrm{~mm}$ to $5 \mathrm{~mm}$. Their localization also are different from the conventional: robotic punctures are more distant form each other and form surgical camp due to optical system and robot's arms which prevent their collision. At the referred case, the punctures were done some $\mathrm{cm}$ above the usual region in laparoscopy. The ones located at flanks were almost positioned at hyponchondrium and umbilical, slightly above them. This might put the esthetic aspect into risk. Technically, the robot-assisted surgery proved to be as efficient as conventional laparoscopy and still provides 
ergonomic and $3 \mathrm{D}$ vision advantages. It was necessary a higher operative time to remove the structures so the surgeon can control, besides the camera, only two arms simultaneously.

\section{CONCLUSIONS}

Robotic surgery is an attractive modality of minimallyinvasive surgery and have several technological advantages compared to standard laparoscopic surgery. Major advantages are stable camera platform, three-dimensional imaging, excellent ergonomics, tremor elimination and instruments with multiple degrees of freedom. The feasibility and the safety of robotic colorectal surgery was confirmed, however future larger studies will be necessary to evaluate the real benefits of this technology considering its high cost and increasing operative time.

Averbach M, Popoutchi P, Marques Jr OW, Abdalla RZ, Podgaec S, Abrão MS. Retossigmoidectomia laparoscópica robô-assistida - Relato de caso pioneiro no Brasil. Panorama atual da cirurgia robótica colorretal. Arq Gastroenterol. 2010;47(1):116-8.

RESUMO - A cirurgia laparoscópica colorretal é considerada tecnicamente factível e segura, com resultados oncológicos comparáveis à cirurgia aberta. A cirurgia robótica é uma atraente modalidade de cirurgia minimamente invasiva, com algumas vantagens claras sobre a laparoscopia convencional O objetivo deste trabalho é descrever a experiência pioneira da cirurgia colorretal robô-assistida no Brasil. A paciente de 35 anos operada com auxílio do sistema $d a$ Vinci $i^{\circledR}$ tinha endometriose profunda, com envolvimento do reto. É feita ampla revisão da literatura, discutindo não apenas a indicação e segurança da cirurgia robótica colorretal, mas também seus reais benefícios.

DESCRITORES - Robótica. Laparoscopia. Endometriose, cirurgia. Colo sigmóide, cirurgia. Reto, cirurgia.

\section{REFERENCES}

1. Baik SH, Ko YT, Kang CM, Lee WJ, Kim NK, Sohn SK, Chi HS, Cho CH Robotic tumor-specific mesorectal excision of rectal cancer: short-term outcome of a pilot randomized trial. Surg Endosc. 2008;22:1601-8.

2. D'Annibale A, Morpurgo E, Fiscon V, Trevisan P, Sovernigo G, Orsini C, Guidolin D. Robotic and laparoscopic surgery for treatment of colorectal diseases. Dis Colon Rectum. 2004;47:2162-8.

3. Pigazzi A, Ellenhorn JD, Ballantyne GH, Paz IB. Robotic-assisted laparoscopic low anterior resection with total mesorectal excision for rectal cancer. Surg Endosc. 2006;20:1521-5.

4. Spinoglio G, Summa M, Priora F, Quarati R, Testa S. Robotic colorectal surgery: first 50 cases experience. Dis Colon Rectum. 2008;51:1627-32.

5. Weber PA, Merola S, Wasielewski A, Ballantyne GH. Telerobotic-assisted laparoscopic right and sigmoid colectomies for benign disease. Dis Colon Rectum. 2002;45:1689-94.

Recebido em 12/8/2009. Aprovado em 9/9/2009. 